\title{
Incidental Finding of Annular Pancreas in a Routine Cadaveric Dissection: Case Report
}

\author{
Mythraeyee Prasad $^{1} \quad$ Theresa Susan Kuriakose $^{1}$ Sipra Rout $^{10}$ \\ ${ }^{1}$ Department of Anatomy, Christian Medical College, Vellore, Tamil \\ Nadu, India \\ Address for correspondence Sipra Rout, MD, DNB, Department of \\ Anatomy, Christian Medical College, Vellore, Tamil Nadu, 632002, \\ India (e-mail: siprarout@gmail.com).
}

J Morphol Sci 2019;36:299-302.

\begin{abstract}
Keywords

- annular pancreas

- congenital anomaly

- duodenal obstruction

- pancreatic bud

Annular pancreas is a rare congenital anomaly that results from the malrotation of the ventral pancreatic bud. The presentation of annular pancreas varies: it can be asymptomatic or present clinical symptoms of duodenal obstruction that can affect all age groups, from newborns to adults. In the present case report, we describe a complete type of annular pancreas at the level of the second part of the duodenum, which was an incidental finding in a prosected specimen. This anomaly has significant clinical relevance to clinicians and radiologists due to its variable presentation. The embryological, clinical and radiological aspects of this congenital anomaly are discussed in detail in the present article.
\end{abstract}

\section{Introduction}

The pancreas is a retroperitoneal organ situated within the Cshaped loop of the descending part of the duodenum across the posterior abdominal wall. It has four anatomical parts: head, neck, body and tail, as well as an uncinate process. ${ }^{1}$ The pancreas develops from the fusion of ventral and dorsal pancreatic buds at the junction of the foregut and midgut during the fourth week of gestation. It requires a complex sequence of events, such as the fusion of the ventral bud with the dorsal pancreatic bud along with the rotation of the duodenum. ${ }^{2}$ Therefore, due to its complex development, several congenital anomalies are associated with the embryonic development of the pancreas.

Annular pancreas (AP) is one such rare congenital anomaly that is due to an error in rotation, resulting in the formation of a pancreatic tissue ring that partially or completely encircles the second part of the duodenum. It is a rare type of morphological congenital anomaly, with an estimated incidence of 1 out of 12,000-15,000 newborns. Though it affects mostly newborns, constituting around $1 \%$ of all intestinal obstructions in the pediatric age group, in late adulthood its presentation mimics a wide variety of complications, such as pancreatitis, peptic ulcer, duodenal obstruction, perforation and peritonitis, which makes its diagnosis difficult yet indispensable.

received

July 3, 2019

accepted

July 20, 2019
DOI https://doi.org/

10.1055/s-0039-1696694. ISSN 2177-0298.
The present case report deals with an incidental finding on a prosected specimen of an AP with an intact second part of the duodenum during a regular undergraduate class.

\section{Case Report}

During a regular undergraduate Bachelor of Medicine, Bachelor of Surgery (MBBS), anatomical dissection, a prosected pancreas specimen with an intact second part of the duodenum and spleen was identified. This prosected specimen had been obtained earlier from one of the cadavers used for dissection. Thus, the age, sex and medical history of the cadaver from which this specimen was procured could not be traced. These cadavers used for the purpose of research and teaching of undergraduate medical students were donated to the Department of Anatomy, Christian Medical College. Since the college is located in Vellore, India, we assumed that the cadaver was of Southern Indian origin.

This prosected specimen was identified as a case of complete AP with a ring of pancreatic tissue encircling the second part of the duodenum. This band of pancreatic tissue began as a continuation of the head of the pancreas, and traversed horizontally on the anterior aspect of the second part of the duodenum toward the right side, laterally and then posteriorly,

Copyright $\odot 2019$ by Thieme Revinter Publicações Ltda, Rio de Janeiro, Brazil

\section{License terms}

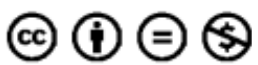




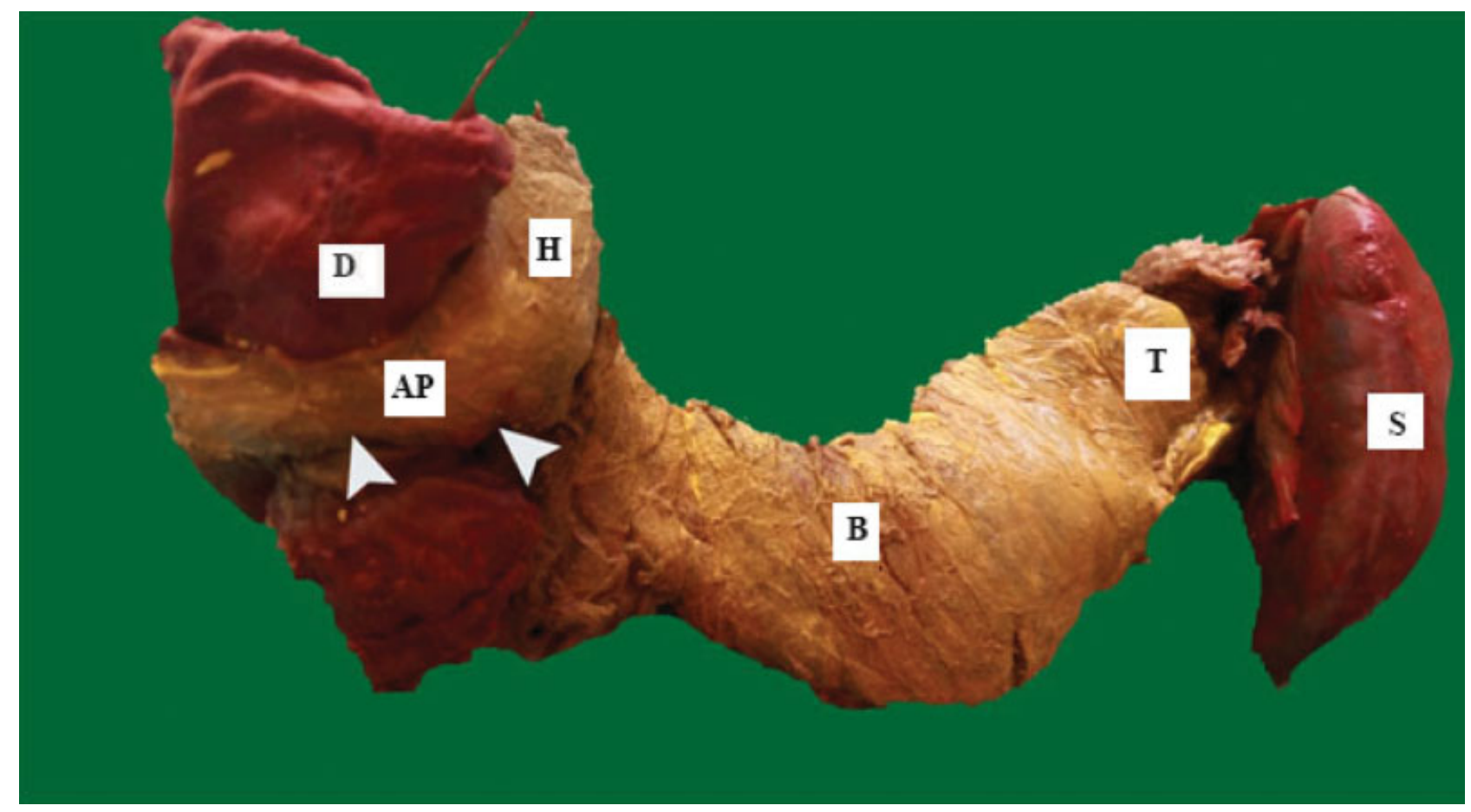

Fig. 1 Anterolateral view of the annular band of pancreatic tissue completely encircling the second part of the duodenum. Abbreviations: AP, annular pancreas; B, body of the pancreas; $\mathrm{D}$, duodenum; $\mathrm{H}$, head of the pancreas; $\mathrm{S}$, spleen; $\mathrm{T}$, tail of the pancreas.

thus completely surrounding the second part of the duodenum. It became continuous with the head of the pancreas on the posterior aspect ( $\mathbf{- F i g}$. 1). The color and texture of the pancreatic tissue ring was similar to that of the rest of the pancreas. The width of the AP was not uniform throughout the duodenum. We measured the width at three sites: anteriorly, it had $1.5 \mathrm{~cm}$, laterally, it had $1.8 \mathrm{~cm}$, and posteriorly, it had $2 \mathrm{~cm}$. The margins of this band were well-defined and showed no adhesion to the duodenal wall. However, a constricted lumen of the second part of the duodenum was observed encircled by the pancreatic tissue ring. In addition, the duodenal luminal diameter showed an appreciable dilation above the level of the annular band, as compared with the distal part. Upon examination, the neck, body and tail of the pancreas, along with spleen, were found to be normal. As this was a prosected specimen, we were unable to observe and comment on the relevant anatomic findings of the surrounding area in the cadaver.

\section{Discussion}

The AP was first reported by Tiedemann in 1818, but it was spotted in autopsy material in 1862 by Ecker, who named it after the ring of pancreatic tissue as "annular pancreas". ${ }^{3,4}$ It is a rare variety of congenital anomaly, occurring in every $12,000-15,000$ births. $^{5}$ The true prevalence of AP in a specific population has not yet been reported. However, a few studies on endoscopic retrograde cholangiopancreatography (ERCP) have shown a prevalence of 1 in 250 or 400 cases per 100,000 adults. ${ }^{6}$ In an autopsy series, the prevalence of AP ranged from $5-15$ per 100,000 adults. $^{7}$
The development of the pancreas begins with the formation of a dorsal and ventral pancreatic bud in the corresponding mesenteries of the duodenum during the fourth week of gestation. By the seventh week, the rotation of the duodenum causes the ventral bud to also rotate and course behind the duodenum to fuse with the dorsal pancreatic bud. The dorsal pancreatic bud forms the upper part of the head, neck, body and tail of the pancreas, whereas the ventral bud forms the lower part of the head and the uncinate process. Sometimes, the ventral bud splits into right and left parts. Later, a faulty migration and fusion of these two parts of the ventral pancreatic bud along with the dorsal pancreatic bud result in a band of pancreatic tissue surrounding the descending part of the duodenum, constricting the duodenal lumen at the site. This annular mass of pancreatic tissue maintains its continuity with the head tissue. Numerous theories have been put forward to explain the development of AP, and, among them those by Lecco $^{8}$ and Baldwin ${ }^{9}$ are widely accepted. These authors postulate that the faulty migration of the ventral pancreatic bud results in a variable band of pancreatic tissue around the second part of the duodenum. ${ }^{8,9}$ Further studies in this line have highlighted the role of the hedgehog signaling pathway in the development of this anomaly. One study ${ }^{10}$ hypothesized the overexpression of the ventral-specific gene transmembrane 4 superfamily member 3 (tm $4 \mathrm{sf} 3$ ), which plays a role in the development of this anomaly. ${ }^{10}$ On the other hand other theories postulate that the primary duodenal stenosis results in a band of pancreatic tissue around it. ${ }^{11}$ Alternatively, Glazer and Margulis ${ }^{12}$ proposed that hypertrophy or atrophy of the ventral and dorsal pancreatic buds might be associated with the development of AP. ${ }^{12}$ Apparently, the AP is associated with variable ductal abnormalities, and, based on that, it has been 
classified into six types, taking into account the drainage site of the main pancreatic duct. ${ }^{13}$

Children usually present with symptoms of gastrointestinal (GI) obstruction, such as poor feeding, vomiting and abdominal distention in the first weeks of life. A few cases of the association of the AP with duodenal ulcer in childhood have also been reported by Fu et al. ${ }^{14}$ Previous studies have reported that the occurrence of AP is as common in adults as it is in children. ${ }^{15,16}$

In adults, it can remain asymptomatic until diagnosed as an incidental finding during routine radiological investigations, or present with secondary clinical symptoms of GI obstruction like nausea, vomiting, abdominal pain etc. In adults, the AP usually presents around the second to the fifth decades of life. ${ }^{15}$ The severity of this condition depends on its type, whether complete or incomplete, and this diagnosis is considered an important factor from the clinical and management points of view. In around $75 \%$ of the cases, the ring of tissues is incomplete, while in $25 \%$ it completely encircles the duodenum. ${ }^{17}$ The severe form, which compromises the duodenal lumen, mandates immediate surgical intervention. ${ }^{18,19}$ Other clinical complications, like obstructive jaundice, pancreatitis, peptic ulcer, and peritonitis secondary to perforation of the duodenum, have been reported. ${ }^{19}$ A strong association with several other congenital anomalies, such as esophageal atresia, tracheoesophageal fistula, imperforate anus, congenital heart disease, Hirschprung disease, malrotation of the midgut, and Down syndrome have been reported in conjunction with $\mathrm{AP}^{20}$ Although this condition does not have a well-established genetic basis, around $42 \%$ of Indian hedgehog $(\mathrm{IHH})$ mutant mice developed AP. ${ }^{21}$ However, how IHH gene loss is associated with development of AP is not yet established. Moreover, isolated case reports of familial AP have also been documented, suggesting a genetic basis for the development of this anomaly. ${ }^{22}$ A rare presentation of AP has been documented by Li et $\mathrm{al}^{23}$ in an 8-yearold girl with sparse scalp hair, bulbous nose, thin upper lip, broad eyebrows, phalangeal abnormalities in both hands and toes, multiple exostoses, mild intellectual impairment and severe malnutrition, presumably suffering from trichorhinophalangeal syndrome type II, a rare autosomal dominant genetic disorder affecting the craniofacial and skeletal development, which is associated with loss of functional copies of the TRPS1 gene at 8q23.3 and the EXT1 gene at 8q24.11. ${ }^{23}$

Glazer and Margulis, ${ }^{12}$ Sandrasegaran et $\mathrm{al}^{15}$, Maker et $\mathrm{al}^{24}$ and Jarry et $\mathrm{al}^{25}$ have reported that the AP affects the second part of the duodenum in $74 \%$ of cases. This is supported by cadaveric case reports by Russo and Ugon, ${ }^{26}$ and Vinoth et al. ${ }^{19}$ Nayak et $\mathrm{al}^{27}$ reported that in $21 \%$ of the cases the AP has also been found around the first and third parts of the duodenum. ${ }^{27}$

The AP can remain asymptomatic in adults and go unnoticed throughout life, or it can present during the second to fifth decades of life with clinical symptoms like abdominal pain, vomiting, peptic ulcer, pancreatitis (acute or chronic) and biliary obstruction. ${ }^{15}$ The late onset of the obstructive symptoms in the elderly has been attributed to the development of pancreatitis (13-22\%) due to insufficient drainage of the pancreatic juice through the annular duct, leading to stagnation and initiation of an inflammatory cascade. ${ }^{16,28}$

With the advent of different types of diagnostic and therapeutic imaging, such as ultrasonography (USG), computed tomography (CT), magnetic resonance imaging (MRI), ERCP, and magnetic resonance cholangiopancreaticography (MRCP), the awareness regarding this kind of incidental finding of APs gained paramount clinical significance, and became important for clinicians and radiologists. ${ }^{15}$ When symptomatic, the aforementioned imaging modalities can aid in the diagnosis. The MRCP appears to be the best noninvasive alternative method for the diagnosis of AP, since the ERCP may not be feasible at times due to the variable amount of duodenal obstruction by the pancreatic ring. ${ }^{29}$

The management of AP is usually primarily aimed at relieving the obstruction. Surgical interventions like enteroenterostomy are being commonly performed as a treatment modality. ${ }^{24,30}$ Duodenoduodenostomy or duodenojejunostomy are the safest and most successful way of bypassing the annular constriction. ${ }^{31}$ In cases of AP associated with suspicion of periampullary malignancy, pancreatolithiasis and localized chronic pancreatitis, duodenopancreatectomy might be the treatment option. ${ }^{12,32}$ However, resection of the AP band is usually avoided because of severe postoperative complications, including fistula formation and pancreatitis, with incomplete permanent cure rate. ${ }^{33}$

In conclusion, any symptoms of intestinal obstruction, including mild ones, such as vomiting and abdominal pain, at any age, can raise the suspicion of AP, though it is rare. Thus, this should be kept in mind during the investigation, and the AP must be ruled out. Asymptomatic cases can pose a threat and cause complications during various abdominal surgeries, such as kidney transplants and liver surgeries. Any inadvertent injury might lead to a leak of the active pancreatic enzymes in the pancreatic juice into the surrounding area.

Hence, this rare congenital anomaly, a complete AP around the second part of the duodenum in an adult (that can remain asymptomatic or symptomatic) has significant clinical relevance to clinicians and radiologists. But the importance and effect of this anomaly in the present case report could not be appreciated, since it was an incidental finding in a prosected specimen with unknown cause of death.

\section{Conflicts of Interest}

The authors have none to declare.

\section{References}

1 Susan and Standring. Gray's Anatomy. 40th ed. Elsevier

2 Sadler TW. Langman's Medical Embryology, 8th ed. Lippincott Williams \& WilkinsPhiladelphia, PA2000

3 Tiedemann F. Über die Verschiedenheiten des Ausführungsganges der Bauchspeicheldrüse bei den Menschen und Säugetieren. Dtsch Arch Physiol 1818:403

4 Ecker A. Bildungsfchler des pancreas und Herzens. Z Art Med 1862:354

5 Sirasanagandla SR, Nayak SB, Bhat KM. A rare congenital anomaly of the pancreas: a cadaveric case report. JOP 2013;14(04): 454-457 
6 Baggott BB, Long WB. Annular pancreas as a cause of extrahepatic biliary obstruction. Am J Gastroenterol 1991;86(02):224-226

7 Ravitch MM, Woods AC Jr. Annular pancreas. Ann Surg 1950;132 (06):1116-1127

8 Leeco TM. Zur Morphologie des Pancrease. Sitzungsb Akad Wiss Math-Nat Ki Wien 1910;119:391-406

9 Baldwin WM. A specimen of annular pancreas. Anat Rec 1910; 4:299-304

10 Jarikji Z, Horb LD, Shariff F, Mandato CA, Cho KW, Horb ME. The tetraspanin $\mathrm{Tm} 4 \mathrm{sf3}$ is localized to the ventral pancreas and regulates fusion of the dorsal and ventral pancreatic buds. Development 2009;136(11):1791-1800

11 Pantoja E, Nagy F, Thomas HA Jr, Zambernard J, Bartley MC. Annular pancreas. Med Radiogr Photogr 1985;61(03):2-9

12 Glazer G, Margulis A. Use of ERCP in Annular pancreas. Radiology 1979;133:303-306

13 Yogi Y, Kosai S, Higashi S, Iwamura T, Setoguchi T. Annular pancreas associated with pancreatolithiasis: a case report. Hepatogastroenterology 1999;46(25):527-531

14 Fu PF, Yu JR, Liu XS, Shen QY, Zheng SS. Symptomatic adult annular pancreas: report of two cases and a review of the literature. Hepatobiliary Pancreat Dis Int 2005;4(03):468-471

15 Sandrasegaran K, Patel A, Fogel EL, Zyromski NJ, Pitt HA. Annular pancreas in adults. AJR Am J Roentgenol 2009;193(02):455-460

16 Zyromski NJ, Sandoval JA, Pitt HA, et al. Annular pancreas: dramatic differences between children and adults. JAm Coll Surg 2008;206(05):1019-1025, discussion 1025-1027

17 Kandpal H, Bhatia V, Garg P, Sharma R. Annular pancreas in an adult patient: diagnosis with endoscopic ultrasonography and magnetic resonance cholangiopancreatography. Singapore Med J 2009;50(01):e29-e31

18 Noh TH, Lee SE, Park JM. Laparoscopic treatment of annular pancreas in adults: report of a case. Korean J Hepatobiliary Pancreat Surg 2012;16(01):43-45

19 Vinoth S, Sankaran PK, Jeevapriya T, Sivanandan R. Annular pancreas - A rare variation and its clinical significance. The Health Agenda 2015;3(03):108-111
20 Tadokoro H, Takase M, Nobukawa B. Development and congenital anomalies of the pancreas. Anat Res Int 2011;2011:351217

21 Hebrok M, Kim SK, St Jacques B, McMahon AP, Melton DA. Regulation of pancreas development by hedgehog signaling. Development 2000;127(22):4905-4913

22 Hendricks SK, Sybert VP. Association of annular pancreas and duodenal obstruction-evidence for Mendelian inheritance? Clin Genet 1991;39(05):383-385

23 Li Q, Zhang Z, Yan Y, et al. Annular pancreas in Trichorhinophalangeal syndrome type II with 8q23.3-q24.12 interstitial deletion. Mol Cytogenet 2015;8:95

24 Maker V, Gerzenshtein J, Lerner T. Annular pancreas in the adult: two case reports and review of more than a century of literature. Am Surg 2003;69(05):404-410

25 Jarry J, Wagner T, Rault A, Sa Cunha A, Collet D. Annular pancreas: a rare cause of acute pancreatitis. JOP 2011;12(02):155-157

26 Russo A, Ugon GA. Annular pancreas: case report and review of literature. Eur J Anat 2015;19(02):197-200

27 Nayak S, Pamidi N, George BM, Guru A. A strange case of double annular pancreas. JOP 2013;14(01):96-98

28 Urushihara N, Fukumoto K, Fukuzawa H, et al. Recurrent pancreatitis caused by pancreatobiliary anomalies in children with annular pancreas. J Pediatr Surg 2010;45(04):741-746

29 Chevallier P, Souci J, Buckley MJ, Oddo F, Hastier P, Diaine B. Annular pancreas: MR imaging including MR cholangiopancreatography (MRCP). Pancreas 1999;18(02):216-218

30 Paraskevas G, Papaziogas B, Lazaridis C, Gigis P, Papaziogas T. Annular pancreas in adults: embryological development, morphology and clinical significance. Surg Radiol Anat 2001;23(06): 437-442

31 Ladd AP, Madura JA. Congenital duodenal anomalies in the adult. Arch Surg 2001;136(05):576-584

32 Shan YS, Sy ED, Lin PW. Annular pancreas with obstructive jaundice: beware of underlying neoplasm. Pancreas 2002;25(03):314-316

33 Urayama S, Kozarek R, Ball T, et al. Presentation and treatment of annular pancreas in an adult population. Am J Gastroenterol 1995;90(06):995-999 